\title{
A Survey of Self-Reported Food Allergy and Food-Related Anaphylaxis among Young Adult Students at Kuwait University, Kuwait
}

\author{
Fatima Ali \\ Department of Medicine, Faculty of Medicine, Kuwait University, Al-Jabriya, Kuwait
}

\section{Keywords}

Food allergy · Anaphylaxis · Kuwait

\begin{abstract}
Objectives: To conduct a survey on self-reported food allergy to milk, egg, peanuts, tree nuts, fish, shellfish, wheat, and sesame, as well as reported food-related anaphylaxis and epinephrine prescription practices among Kuwaiti students attending Kuwait University. Subjects and Methods: One thousand questionnaires that included data on age, gender, presence of food allergies, and associated details were distributed. All participants reporting an allergy were categorized as having a perceived food allergy. Those with a convincing clinical history and history of undergoing diagnostic food allergy testing were further categorized as having a probable food allergy. Results: Of the 1,000 questionnaires, $865(86.5 \%)$ were completed. Of the 865 students, 104 $(12.02 \%)$ reported food allergy (perceived), and 47 of these (45.19\%) were probable food allergies. For milk (46.7\%), peanut $(35.7 \%)$, fish $(60 \%)$, and sesame $(50 \%)$, probable food allergy occurred in early childhood ( $\leq 5$ years) while those of egg (44.4\%) and wheat (57.1\%) occurred in late childhood (6-10 years), and shellfish (40\%) occurred in early adolescence (11-15 years). Of the 47 students with a probable food allergy, 28 (59.6\%) were moderate to severe: 20 (71\%) of these moderate-to-severe allergy cases reported at least 1
\end{abstract}

\begin{tabular}{ll}
\hline KARGER & (c) 2017 S. Karger AG, Basel \\
$\begin{array}{l}\text { E-Mail karger@karger.com } \\
\text { www.karger.com/mpp }\end{array}$ & $\begin{array}{l}\text { This is an Open Access article licensed under the terms of the } \\
\text { Creative Commons Attribution-NonCommercial 3.0 Un- } \\
\text { ported license (CC BY-NC) (www.karger.com/OA-license), } \\
\text { applicable to the online version of the article only. Distribu- } \\
\text { tion permitted for non-commercial purposes only. }\end{array}$
\end{tabular}

food-related anaphylactic episode while 8 (29\%) denied such episodes. Equally important, of the 28 students, 6 (21\%) received an autoinjectable epinephrine prescription, while 22 (79\%) did not receive any. Conclusions: In this study the reported occurrence of perceived food allergy was low and probable food allergy occurred mostly in early childhood. Milk, egg, and nut allergies were the most commonly reported in both groups.

(c) 2017 S. Karger AG, Basel

\section{Introduction}

Food allergy is a complex immunologically mediated disorder that affects all age groups across the globe. Based on numerous prevalence studies, it is estimated to afflict up to $8 \%$ of children and $5 \%$ of adults $[1,2]$. Within the last 2 decades this issue has become more widely discussed in scientific, public, and media circles as prevalence, awareness, and ramifications of this condition have all increased, especially given the significant association between food allergy, patient morbidity, and mortality [1, 3]. There is a growing body of literature from developed nations concerning the epidemiology of food allergies amongst their pediatric and adult populations $[1,2,4,5]$. Given the health, psychological, nutritional, and financial impact of food allergy, it is concerning to learn that the

\section{Fatima Ali}

Department of Medicine, Faculty of Medicine

Kuwait University Health Science Center, Al-Jabriya Campus

Al-Jabriya (Kuwait)

E-Mail fatimakhalilali@hsc.edu.kw 
prevalence of food allergies appears to be increasing throughout those countries [5-7]. Few studies have been done on food allergy in the Middle East [8-11], and epidemiological food allergy-related research has not been done in Kuwait. This self-reported, survey-based study was designed to estimate the occurrence of food allergies and food-related anaphylaxis to common food allergens in a population of young Kuwaiti adults attending Kuwait University, Kuwait.

\section{Subjects and Methods}

\section{Selection of Study Population}

Inclusion criteria for the survey consisted of being a Kuwaiti student (defined as a student with at least 1 parent who holds the Kuwaiti nationality); being 17-30 years of age; and attending classes at Kuwait University in the Al-Jabriyah, Kaifan, and Al-Khaldiyah campuses. Non-Kuwaiti students (defined as students with neither parent holding the Kuwaiti nationality) or those outside the stated age range were excluded. The survey was conducted over a period of 9 months, from May 2015 to January 2016.

\section{Questionnaire}

A standardized questionnaire was based on the previously developed survey by Sicherer et al. [5, 6] and Ben-Shoshan et al. [2], with some questions modified to accommodate the indigenous requirements of the local population. The questionnaire was first written in the English language, then translated to Arabic by the Al-Kindi Office for Printing and Translation in Hawally, Kuwait. The questions included age, gender, and the presence of any current food allergy in the 8 food groups mentioned previously [2]. For those indicating the presence of a food allergy, they were asked further details regarding age at the initial appearance of symptoms and provided with the following 4 categories: early childhood, $\leq 5$; late childhood, 6-10; early adolescence, 11-15; and late adolescence, 16-19 years. Students were also asked about the average time between food ingestion to onset of symptoms, and typical symptoms associated with the food exposure. The questions focused on IgE-mediated symptoms (urticaria, pruritus, angioedema, and rhinoconjunctivitis), respiratory symptoms (wheezing, coughing, and cyanosis), gastrointestinal symptoms (vomiting and diarrhea), and symptoms of circulatory collapse (dizziness and loss of consciousness). The participants were also asked about any subsequent reexposure to the same offending food since diagnosis and if exposure caused recurrence of the symptoms, or conversely if they had completely avoided and have continued to avoid that food since the diagnosis. A participant was considered to have a current food allergy in 2 situations: the student reported a food allergy with symptom recurrence upon food exposure, or the student had a history of food allergy and has entirely avoided the offending food since diagnosis. The latter group was included as there was no way to adequately assess their present allergy status without undergoing further investigations and possibly an oral food challenge. Participants who indicated that they had been diagnosed with a food allergy but had since ingested the offending food without recurrence of any symptoms were not considered to have a current food allergy and were excluded from this group. In addition to the above questions regarding food allergy, the students were asked to indicate who had made the diagnosis (options included an allergy specialist, a nonallergy specialist, or self-diagnosis without consulting any health care professional) as well as any episodes of food-related anaphylaxis and epinephrine administration. For those indicating a food allergy diagnosis by a physician, the students were asked what method was used to achieve that diagnosis (food allergen specific skin prick testing, food allergenspecific IgE ImmunoCAP assay, oral challenge, or any combination of the above). Finally, the questionnaire included the option to allow the research team to access medical records to confirm the food allergy. To improve the accuracy of the study, attempts were made to obtain the confirmatory food allergy test results of the students from their physicians.

\section{Survey Method}

A paper questionnaire was designed to solicit student responses and a proctor distributed the questionnaires among the students immediately after their classes had concluded. One thousand surveys in total were distributed among the students on the various Kuwait University campuses. Before distributing the survey, the participation criteria were announced to each class. Of the 1,000 students, 26 indicated to the proctor that they could not participate due to their nationality and were thus excluded. Hence, the questionnaires were distributed to the other 974 students. The survey required that the participant circle the most appropriate answer for each question. The distributed questionnaire was available in both English and Arabic, depending on student preference, then collected after $10 \mathrm{~min}$. Three proctors and the author were available to answer any questions the students might have regarding the survey. Written, informed consent was obtained from each student. The study was approved by the Kuwait University Health Science Center Ethics Committee.

\section{Food Allergy Definitions}

In this study, an allergic reaction was defined as mild if it involved pruritus, urticaria, or rhinoconjunctivitis; moderate if it involved angioedema, throat tightness, gastrointestinal complaints, or respiratory difficulties (excluding wheezing); and severe if it involved wheezing, cyanosis, or circulatory collapse. A convincing clinical history of an allergic food reaction was defined as a participant who developed at least 2 mild signs/symptoms or 1 moderate or 1 severe sign/symptom that was most likely IgE mediated. These signs/symptoms should occur within $2 \mathrm{~h}$ after contact with the offending food. Participants who complained of only gastrointestinal symptoms were not considered to have a true IgE-mediated food allergy. Two definitions of food allergy were used based on similar definitions established previously by Ben-Shoshan et al. [2]. The first category was perceived food allergy and encompassed all cases of self-reported food allergy regardless of clinical history, method of diagnosis, or the presence of any confirmatory tests. The second category, probable food allergy, referred to subjects reporting a food allergy which was accompanied by a convincing clinical history for an IgE-mediated reaction and that was evaluated by a physician. In addition, all students had to report undergoing at least 1 confirmatory test (food allergen-specific IgE ImmunoCAP assay, food allergen-specific skin prick testing, oral food challenge, or any combination of those 3 ) to be included in this second category. 
Statistical Analysis

The data analysis and graphical presentation were done using the computer software Statistical Package for Social Sciences (SPSS version 23.0; IBM Corp, Armonk, NY, USA). The descriptive statistics for categorical variables are summarized as frequencies and percentages, while continuous variables and age are summarized as means $\pm \mathrm{SD}$ along with range.

\section{Results}

\section{Participation Rate}

Of the 974 questionnaires, 865 were completed and returned, giving a response rate of $88.8 \%$. Of the 865 respondents, 668 (77.2\%) were females and 197 (22.8\%) were males. The mean age of the respondents was $20.7 \pm$ 1.2 years.

\section{Reports of Occurrence}

Of the 865 respondents, a total of 104 (12.02\%) reported a food allergy (perceived) and 47 of these (45.2\%) were categorized as having a probable food allergy. The distribution of both perceived and probable occurrence of food allergy is shown in Table 1. No significant difference was found between the proportions of perceived and probable food allergies with respect to each food item $(p>0.05)$.

The reported occurrences of perceived food allergy to the different foods are shown in Table 1. The highest occurrence of perceived food allergy was to milk ( $n=48$; $46.2 \%)$ and the lowest was to sesame $(n=6 ; 5.8 \%)$. Of the 104 students in the perceived food allergy group, 90 $(86.5 \%)$ reported self-diagnosis or consulting an acquaintance (e.g., a parent, friend, or colleague) without ever consulting any health care provider. The remaining 14 (13.5\%) students reported consulting a physician for the symptoms, but indicated that the physician did not use any confirmatory testing to reach the diagnosis.

The occurrence of probable food allergy to different foods is also shown in Table 1. The highest occurrence was to egg $(n=18 ; 38.3 \%)$ and lowest to sesame $(n=4$; $8.5 \%)$. Twenty-three $(48.93 \%)$ students reported an allergy to 1 food item. Twenty-four (51.06\%) students reported an allergy to 2 food items or more. All participants with a probable food allergy reported being diagnosed by a physician, and also reported that the physician used 1 or more confirmatory tests. Ten $(21.27 \%)$ students reported undergoing more than 1 test. Regarding individual tests, 36 (76.6\%) out of 47 students reported undergoing food allergen-specific IgE blood testing. Thirteen (27.6\%) and 8 (17\%) students reported undergoing skin prick testing or oral food challenge, respectively. At-

Food Allergy at Kuwait University
Table 1. Perceived and probable food allergy occurrence among young Kuwaiti adults at Kuwait University according to type of food

\begin{tabular}{llcl}
\hline Food allergy & $\begin{array}{l}\text { Perceived, } n(\%) \\
(N=104)\end{array}$ & $\begin{array}{l}\text { Probable, } n(\%) \\
(N=47)\end{array}$ & $p$ value \\
\hline Milk & $48(46.2)$ & $15(31.9)$ & 0.143 \\
Egg & $32(30.8)$ & $18(38.3)$ & 0.469 \\
Peanut & $20(19.2)$ & $14(29.8)$ & 0.220 \\
Tree nut & $22(21.2)$ & $14(29.8)$ & 0.344 \\
Fish & $14(13.5)$ & $5(10.6)$ & 0.826 \\
Shellfish & $22(21.2)$ & $10(21.3)$ & 0.843 \\
Wheat & $12(11.5)$ & $7(14.9)$ & 0.756 \\
Sesame & $6(5.8)$ & $4(8.5)$ & 0.786 \\
\hline
\end{tabular}

tempts were made to obtain these results from their physician in order to increase the accuracy of the study. However, those results could not be obtained: 30 students declined to allow contact with their physician for the purpose of this study, and 15 students could not provide adequate contact details of their physician. Two students gave permission and contact details for their physician. However, neither physician provided any confirmatory results. Subsequently, these efforts had to be abandoned.

\section{Reaction Characteristics, Specific Symptoms}

Distribution, and Anaphylaxis

Further analysis of probable food allergy based on age groups is shown in Table 2. The majority of initial allergic food reactions were reported to occur during early childhood and least frequently during late adolescence. In general, with milk (46.7\%), peanuts (35.7\%), fish (61\%), and sesame (50\%), probable food allergy occurred in early childhood ( $\leq 5$ years), while those of egg $(44 \%)$ and wheat (57.1\%) occurred in late childhood (6-10 years), and shellfish (40\%) in early adolescence (11-15 years). The distribution of specific symptoms pertaining to each food type is shown in Table 3, with urticaria, pruritus, and angioedema being the most common complaints. Recurrent reactions, as shown in Table 4, were most frequently associated with egg allergy ( $n=13(72.2 \%)$ and least with wheat allergy $(n=1 ; 14.2 \%)$. Of the 47 students with probable food allergy, 19 (40.42\%) were mild, 9 (19.14\%) were moderate, and 19 (40.42\%) were severe. Of the 28 students with moderate or severe food allergy, 20 (71\%) reported at least 1 anaphylactic episode due to food ingestion while 8 (29\%) denied suffering an anaphylactic reaction. Six (21\%) students in that same group received an

Med Princ Pract 2017;26:229-234 231 
Table 2. Probable food allergy occurrences among students at the time of initial reaction according to age group and type of food

\begin{tabular}{llllllllll}
\hline Age group & $\begin{array}{l}\text { Milk, } \\
n(\%)\end{array}$ & $\begin{array}{l}\text { Egg, } \\
n(\%)\end{array}$ & $\begin{array}{l}\text { Peanut, } \\
n(\%)\end{array}$ & $\begin{array}{l}\text { Tree nut, } \\
n(\%)\end{array}$ & $\begin{array}{l}\text { Fish, } \\
n(\%)\end{array}$ & $\begin{array}{l}\text { Shellfish, Wheat, } \\
n(\%)\end{array}$ & $\begin{array}{l}\text { Sesame, } \\
n(\%) \\
n(\%)\end{array}$ & $\begin{array}{l}\text { Total } \\
\text { reactions, } N\end{array}$ \\
\hline Early childhood (<5 years) & $7(21.9)$ & $6(18.8)$ & $5(15.6)$ & $4(12.5)$ & $3(9.4)$ & $3(9.4)$ & $2(6.3)$ & $2(6.3)$ & 32 \\
Late childhood (5-10 years) & $5(20.8)$ & $8(33.3)$ & $3(12.5)$ & $1(4.2)$ & $1(4.2)$ & $1(4.2)$ & $4(16.7)$ & $1(4.2)$ & 24 \\
Early adolescence (10-15 years) & $1(4.2)$ & $3(12.5)$ & $6(25.0)$ & $8(33.3)$ & $1(4.2)$ & $4(16.7)$ & $1(4.2)$ & 0 \\
Late adolescence (16-19 years) & $2(28.6)$ & $1(14.3)$ & 0 & $1(14.3)$ & 0 & $2(28.3)$ & 0 & $1(14.3)$ & 7 \\
\hline
\end{tabular}

Table 3. Specific symptoms reported by Kuwait University students with probable food allergy, categorized by food type

\begin{tabular}{|c|c|c|c|c|c|c|c|c|}
\hline \multirow[t]{2}{*}{ Symptoms } & \multicolumn{8}{|c|}{ Food allergy, $n$} \\
\hline & $\begin{array}{l}\text { milk } \\
(n=15)\end{array}$ & $\begin{array}{l}\text { egg } \\
(n=18)\end{array}$ & $\begin{array}{l}\text { peanut } \\
(n=14)\end{array}$ & $\begin{array}{l}\text { tree nut } \\
(n=14)\end{array}$ & $\begin{array}{l}\text { fish } \\
(n=5)\end{array}$ & $\begin{array}{l}\text { shellfish } \\
(n=10)\end{array}$ & $\begin{array}{l}\text { wheat } \\
(n=7)\end{array}$ & $\begin{array}{l}\text { sesame } \\
(n=4)\end{array}$ \\
\hline Urticaria & 7 & 14 & 9 & 7 & 3 & 4 & 3 & 2 \\
\hline Pruritus & 9 & 15 & 14 & 10 & 5 & 6 & 3 & 2 \\
\hline Angioedema & 8 & 5 & 7 & 8 & 3 & 6 & 3 & 2 \\
\hline Rhinoconjunctivitis & 4 & 1 & 6 & 4 & 4 & 5 & 0 & 1 \\
\hline Respiratory & 2 & 2 & 3 & 3 & 0 & 2 & 0 & 2 \\
\hline Gastrointestinal & 2 & 3 & 1 & 0 & 1 & 1 & 2 & 0 \\
\hline Circulatory collapse & 0 & 0 & 1 & 1 & 0 & 0 & 1 & 0 \\
\hline
\end{tabular}

The student distribution included multiple symptoms for each food type.

Table 4. Characteristics of allergic reactions among participants with probable food allergy

\begin{tabular}{lllllllll}
\hline Allergic reactions; implied & Milk & Egg & Peanuts & Tree nuts & Fish & Shellfish & Wheat & Sesame \\
\hline Participants with at least 1 allergic reaction, $n$ & 15 & 18 & 14 & 14 & 5 & 10 & 7 \\
Participants with recurrent allergic reactions, $n(\%)$ & $7(46.7)$ & $13(72.2)$ & $5(35.7)$ & $7(50.0)$ & $1(20.0)$ & $2(40.0)$ & $1(14.3)$ & $3(75.0)$ \\
Participants with moderate/severe reaction $1, n(\%)$ & $7(46.7)$ & $7(38.9)$ & $11(78.6)$ & $12(85.7)$ & $2(40.0)$ & $7(70.0)$ & $4(57.1)$ & $3(75.0)$ \\
Participants received epinephrine treatment, $n(\%)$ & $1(6.7)$ & $4(22.2)$ & $4(28.6)$ & $4(28.6)$ & $1(20.0)$ & $3(30.0)$ & $2(28.6)$ & $0(0.0)$
\end{tabular}

${ }^{1}$ A reaction is defined as moderate if it involved angioedema, throat tightness, gastrointestinal complaints, or respiratory difficulties (excluding wheezing), and severe if it involved wheezing, cyanosis, or circulatory collapse.

autoinjectable epinephrine pen for the next potential attack from their provider, while 22 (79\%) reported they never received one.

\section{Discussion}

In this study, the overall reported occurrence of food allergy was $12.02 \%$ (perceived), and within the group with perceived food allergy, the occurrence of probable food allergy was $19 \%(n=45)$. Most of the probable food allergy occurred in early childhood. For both groups, allergies to egg, milk, and nuts were the most commonly reported. The difference between perceived and probable food allergy occurrence could indicate that students with a self-reported food allergy, upon careful evaluation, in fact did not have immunological or clinical evidence of a true IgE-mediated allergy. This variation has been reported previously $[2,5,6]$ and hence reflected the widespread misconceptions about the nature of food allergy, its diag- 
nosis, and management among patients and, potentially, physicians $[12,13]$. Patient-related causes could possibly be due to a tendency to interpret any food intolerance, even those with no immunological basis, as an "allergy." Physician-related misconceptions include lack of experience, failure to consider other diagnoses for the patient's symptoms (e.g., lactose intolerance, scombroid fish food poisoning), and underutilization of confirmatory tests to secure a clear diagnosis $[2,14]$.

The study found that $13.5 \%$ of the students in the perceived allergy group consulted a physician for their symptoms, but did not undergo any confirmatory testing. The underuse of diagnostic food allergy testing is associated with potentially adverse consequences, such as patient misdiagnosis, unnecessary avoidance of particular foods, and a detrimental impact on quality of life [15].

The majority of students with milk and egg allergy reported their first reaction occurred during early and late childhood, respectively, which is consistent with the previous report [1]. For the remaining food groups, however, this study did not reflect the age groups documented in other studies $[4,16]$. This discrepancy could be attributed to the small size of the study as well as recall bias, in that participants could not recall their first allergic food reaction but instead recalled a more recent adverse reaction they experienced. Recall bias has been reported by larger studies as well $[2,6]$. Of note, the study found the majority of students with fish and shellfish allergy reported symptom onset at an earlier age compared to the reported typical onset of late adolescence or adulthood $[2,17]$. This result could be due to exposure at an early age to seafood in Kuwait. Seafood is a traditionally important dietary component of countries in the Persian Gulf region, with a per capita fish and shellfish consumption rate of approximately $17 \mathrm{~kg} /$ year reported in Kuwait [18]. Based on this study, however, it is difficult to explain why the occurrence of probable shellfish allergy was greater than fish allergy, especially in the early and late adolescence groups. Most likely, it is due to the survey's limited size and a larger population sample would be needed to assess this finding.

The study found the reported occurrence of probable milk allergy among students was $1.73 \%$, egg allergy $2.08 \%$, and wheat $0.81 \%$. These values exceed those reported in the literature $[7,16]$. Similarly, the reported occurrence rates of probable nut allergy in this study were slightly higher compared to other studies [5]. These studies, however, pertain to larger, more general populations. Therefore, given these factors, and in the absence of confirmatory laboratory data, the true occurrence rates of milk, egg, and wheat allergy in this study are most likely less than estimated.

Over half of students with a probable food allergy were moderate to severe, with $71 \%$ reporting at least one anaphylactic episode due to food ingestion. However, the prescription rate of autoinjectable epinephrine was low. This finding could be due to underutilization of autoinjectable epinephrine as well as significant gaps in anaphylaxis management, both which remain a cause of concern among allergists [19].

The limitations of the study included its small sample size; convenience sampling; noticeable gender bias, with a female to male ratio of 3.4:1; and the lack of confirmatory food allergy tests.

\section{Conclusion}

The study demonstrated a low reported food allergy of $12 \%$. The most commonly reported allergies were to milk, egg, and nuts. The majority of students reported allergy onset during early childhood. Equally important, there was a low rate of autoinjectable epinephrine prescription among the students with moderate-to-severe food allergies.

\section{Acknowledgement}

The author would like to thank Laila Khalild Shareef, Nadiah A. AlSaffar, and Maryam Haji Alipour for their technical assistance and support in conducting this study.

References

Med Princ Pract 2017;26:229-234

1 Sicherer SH, Sampson H: Food allergy: epidemiology, pathogenesis, diagnosis, and treatment. J Allergy Clin Immunol 2014;133:291307; quiz 308.

2 Ben-Shoshan M, Harrington DW, Soller L, et al: A population-based study on peanut, tree nut, fish, shellfish, and sesame allergy prevalence in Canada. J Allergy Clin Immunol 2010;125:1327-1335.

3 Berns SH, Halm E, Sampson H, et al: Food allergy as a risk factor for asthma morbidity in adults. J Asthma 2007;44:377-381.

4 Rona RJ, Keil T, Summers C, et al: The prevalence of food allergy: a meta-analysis. J Allergy Clin Immunol 2007;120:638-646.

5 Sicherer SH, Muñoz-Furlong A, Sampson H: Prevalence of peanut and tree nut allergy in the United States determined by means of a random digit dial telephone survey: a 5-year follow-up study. J Allergy Clin Immunol 2003;112:1203-1207. 
6 Sicherer SH, Muñoz-Furlong A, Sampson H: Prevalence of self-reported peanut, tree nut and sesame allergy in the US determined by a random nationwide telephone survey: results from 1997, 2002 and 2008. J Allergy Clin Immunol 2010;125:AB216.

7 Verrill L, Bruns R, Luccioli S: Prevalence of self-reported food allergy in US adults: 2001, 2006, and 2010. Allergy Asthma Proc 2015;36: 458-467.

8 Dalal I, Binson I, Reifen R, et al: Food allergy is a matter of geography after all: sesame as a major cause of severe IgE-mediated food allergic reactions among infants and young children in Israel. Allergy 2002;57:362-365.

9 Du Toit G, Katz Y, Sasieni P, et al: Early consumption of peanuts in infancy is associated with a low prevalence of peanut allergy. J Allergy Clin Immunol 2008;122:984-991.

10 Al-Hammadi S, Al-Maskari F, Bernsen R: Prevalence of food allergy among children in Al-Ain City, United Arab Emirates. Int Arch Allergy Immunol 2010;151:336-342.
11 Irani C, Maalouly G, Germanos M, et al: Food allergy in Lebanon: is sesame seed the "Middle Eastern" peanut. World Allergy Organ J 2011; 4:1-3.

12 Gupta RS, Springston EE, Smith B, et al: Food allergy knowledge, attitudes, and beliefs of parents with food-allergic children in the United States. Pediatr Allergy Immunol 2010; 21:927-934.

13 Gupta RS, Kim JS, Barnathan JA, et al: Food allergy knowledge, attitudes and beliefs: focus groups of parents, physicians and the general public. BMC Pediatr 2008;8:36.

14 Ben-Shoshan M, Kagan R, Primeau MN, et al: Establishing the diagnosis of peanut allergy in children never exposed to peanut or with an uncertain history: a cross-Canada study. Pediatr Allergy Immunol 2010;21:920-926.
15 Cummings AJ, Knibb RC, King RM, et al: The psychosocial impact of food allergy and food hypersensitivity in children, adolescents and their families: a review. Allergy Eur J Allergy Clin Immunol 2010;65:933-945.

16 Sampson H: Update on food allergy. J Allergy Clin Immunol 2004;113:805-819.

17 Sicherer SH, Muñoz-Furlong A, Sampson H: Prevalence of seafood allergy in the United States determined by a random telephone survey. J Allergy Clin Immunol 2004;114:159165.

18 Resource-detail, FAO, Food and Agriculture Organization of the United Nations. http:// www.fao.org/in-action/globefish/fisheryinformation/resource-detail/en/c/338542/ (accessed February 2, 2016).

19 Kastner M, Harada L, Waserman S: Gaps in anaphylaxis management at the level of physicians, patients, and the community: a systematic review of the literature. Allergy Eur J Allergy Clin Immunol 2010;65:435-444. 